ELECTRONIC LETTER

\title{
A combination of genetic polymorphisms increases the risk of progressive disease in chronic hepatitis $C$
}

\author{
M M Richardson, E E Powell, H D Barrie, A D Clouston, D M Purdie, J R Jonsson
}

J Med Genet 2005;42:e45 (http://www.jmedgenet.com/cgi/content/full/42/7/e45). doi: 10.1136/jmg.2005.032557

\begin{abstract}
Background: There is increasing interest in the influence of host genetic factors on hepatic fibrosis, and whether genetic markers can reliably identify subjects at risk of developing severe disease. We hypothesised that hepatitis $\mathrm{C}$ virus (HCV) infected subjects with progressive fibrosis, classified using strict criteria based on histology at biopsy in addition to disease duration would be more likely to inherit several genetic polymorphisms associated with disease progression compared with subjects with a low rate of disease progression.

Methods: We examined polymorphisms in eight genes that have been reported to have an association with hepatic fibrosis.

Results: Associations between polymorphisms in six genes and more rapidly progressing fibrosis were observed, with individual adjusted odds ratios ranging from 2.1 to 4.5 . The relationship between rapidly progressing fibrosis and possession of $\geqslant 3, \geqslant 4$, or $\geqslant 5$ progression associated alleles was determined and the adjusted odds ratios increased with increasing number of progression associated alleles (9.1, 15.5, and 24.1, respectively). Using logistic regression analysis, a predictive equation was developed and tested using a second cohort of patients with rapidly progressing fibrosis. The predictive equation correctly classified $80 \%$ of patients in this second cohort.

Conclusions: This approach may allow determination of a genetic profile predictive of rapid disease progression in $\mathrm{HCV}$ and identify patients warranting more aggressive therapeutic management.
\end{abstract}

$\mathrm{T}$ he development of advanced fibrosis or cirrhosis is the most significant consequence of infection with the hepatitis $\mathrm{C}$ virus (HCV) since the mortality associated with this infection is largely due to the complications of cirrhosis. ${ }^{1}$ The ability to predict an individual's risk of progressive disease has important prognostic and therapeutic implications. The rate of development of fibrosis varies substantially among subjects and is influenced by a number of factors including gender, age at infection, alcohol consumption, and hepatic steatosis. ${ }^{2-4}$ However, these demographic and environmental factors account for only a small proportion of the variability in the rate of disease progression. ${ }^{5}$

There is increasing interest in the influence of host genetic factors on liver fibrosis, and whether genetic markers can reliably identify subjects at risk of developing severe disease. Many studies have examined the relationship between various gene polymorphisms and fibrosis in patients with chronic liver disease (reviewed in Bataller et $\mathrm{al}^{6}$ ). The genetic factors investigated include human leukocyte antigen class II alleles, mutations in the haemochromatosis gene (HFE) and genes encoding cytokines, inflammatory mediators, enzymes involved in oxidative stress, and proteins involved in lipid metabolism. These studies have produced inconsistent results and it remains difficult to draw firm conclusions from the reported data. For complex diseases, genetic associations are usually of small magnitude with odds ratios of 1.1 to 1.5 , and any single polymorphism accounts for only $1-8 \%$ of the overall disease risk in the population. ${ }^{7}$ Although the risk attributed to an individual polymorphism is very small, the additive effect of several genetic variants from different loci may account for a greater proportion of the disease risk. ${ }^{7}$ However, few studies in chronic liver disease have examined the combined effect of multiple predisposing alleles.

A second issue encountered in the interpretation of these studies, is the method used to categorise subjects into those with a low or high risk of disease progression. Most studies reporting the relationship between genetic polymorphisms and severity of liver disease have been cross-sectional in design and the associations were determined using the stage of fibrosis at a single liver biopsy, irrespective of the duration of HCV infection (reviewed in Yee ${ }^{8}$ ). Within a single centre, the majority of subjects with chronic HCV have minimal or mild fibrosis, but it may be erroneous to assign them to a low risk category if they have a relatively short duration of disease.

We hypothesised that HCV infected subjects with progressive fibrosis would be more likely to inherit several progression associated genetic polymorphisms compared with subjects with a low risk of progressive disease. In order to investigate this, we examined polymorphisms in eight genes (HFE, MTP, APOE, CCR5, SOD2, CTLA4, LDLR, and MPO) that have been reported by other investigators as having an association with hepatic fibrosis. ${ }^{9-17}$ The inheritance of these polymorphisms was examined in the following subjects with chronic HCV: slow progressors (no or minimal fibrosis after 20 years of infection) and those with rapidly progressive fibrosis (Scheuer stage 3 or 4 fibrosis or stage 2 fibrosis within 10 years after infection). We then determined whether the combined effect of inheriting several progression associated genetic polymorphisms influenced the risk of developing progressive fibrosis in a second population of subjects with advanced liver disease due to chronic HCV.

\section{METHODS \\ Patients}

The study involved two groups of subjects seen at the Princess Alexandra Hospital, Brisbane as follows: (1)

Abbreviations: APOE, apolipoprotein $\mathrm{E}$; BMI, body mass index; CCR5, CC chemokine receptor 5; CTLA4, cytotoxic T lymphocyte associated protein 4 ; $\mathrm{HCV}$, hepatitis $\mathrm{C}$ virus; $\mathrm{HFE}$, haemochromatosis gene; LDLR, low density lipoprotein receptor; MPO, myeloperoxidase; MTP, microsomal triglyceride transfer protein; PBMC, peripheral blood mononuclear cells; PCR, polymerase chain reaction; ROC, receiver operating characteristic curve; ROS, reactive oxygen species; SOD2, manganese superoxide dismutase 2; Th cells, T helper cells 
consecutive Caucasian patients $(\mathrm{n}=326)$ with chronic HCV who had undergone liver biopsy prior to antiviral treatment; and $(2)$ subjects $(n=24)$ who received a liver transplant for chronic HCV. Informed consent in writing was obtained from each patient and the study protocol was approved by the University of Queensland and Princess Alexandra Hospital Research Ethics Committee. Diagnosis of chronic HCV was based on standard serological assays and abnormal serum aminotransferase levels (greater than or equal to $1.5 \times$ upper limit of normal) for at least 6 months. All patients were positive for HCV antibody by the second generation ELISA (Abbott Laboratories, North Chicago, IL) with infection confirmed by detection of circulating HCV RNA by polymerase chain reaction (PCR) using the Amplicor HCV assay (Roche, Branchburg, NJ, USA), and were negative for HBsAg or antibodies to human immunodeficiency virus. Date of infection with HCV was recorded as the first year of drug use for subjects infected by intravenous drug use, the date of transfusion in those subjects infected by blood products, or the date of tattoo/needlestick injury. Patients for whom date of infection was unknown and those with other forms of chronic liver disease were excluded from the analysis. Viral genotyping was performed using the Inno-Lipa HCV II assay (Innogenetics, Zwijnaarde, Belgium).

Liver biopsy specimens were fixed in buffered formalin and embedded in paraffin. The degree of inflammation and fibrosis was assessed and graded (by a single pathologist) according to the method of Scheuer. ${ }^{18}$ Steatosis was graded as follows: 0 ( $<5 \%$ hepatocytes affected); 1 ( $5-29 \%$ hepatocytes affected); 2 (30-70\% hepatocytes affected); and 3 (>70\% hepatocytes affected). Iron content was assessed on a scale of 0-4 following Perls' Prussian Blue staining.

A training cohort was identified using patients from group 1 who were categorised into slow progressors and those with rapidly progressive disease on the basis of liver histology and years since acquisition of HCV (fig 1). Patients with slowly progressive disease had no or minimal fibrosis (Scheuer stage 0 or 1 ) on liver biopsy $\geqslant 20$ years after acquisition of HCV. Patients with rapidly progressive disease had Scheuer stage 3 or 4 fibrosis on liver biopsy or stage 2 fibrosis $\leqslant 10$ years after acquisition of HCV. The remaining patients were not included in the training cohort because their rate of disease progression could not be clearly categorised as slow or rapid.

Details about weight, height, and average alcohol intake (g/day) during the preceding 12 months (current alcohol intake) were obtained from all patients at the time of liver

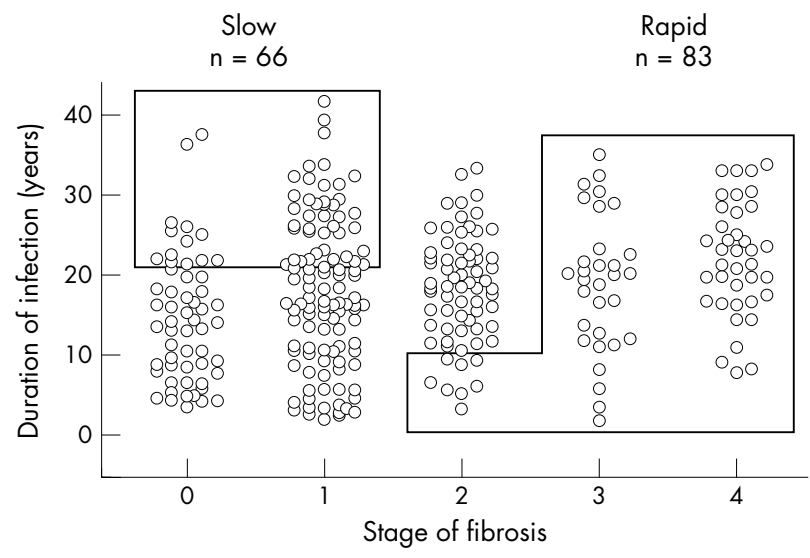

Figure 1 Strategy for selection of a training cohort from patients with chronic HCV $(n=326)$. Patients with slowly progressive disease had no or minimal fibrosis (Schever stage 0 or 1 ) on liver biopsy $\geqslant 20$ years after acquisition of HCV. Patients with rapidly progressive disease had Schever stage 3 or 4 fibrosis on liver biopsy or stage 2 fibrosis $\leqslant 10$ years after acquisition of $\mathrm{HCV}$. biopsy. Information regarding average alcohol intake (g/day) prior to the last 12 months was also obtained (past alcohol intake).

\section{Genotyping}

Genomic DNA was extracted from peripheral whole blood using DNAzol BD Reagent (Invitrogen, Mount Waverly, Australia). Polymorphisms in microsomal triglyceride transfer protein (MTP, $-493 \mathrm{G} \rightarrow \mathrm{T}$ ), cytotoxic $\mathrm{T}$ lymphocyte associated protein 4 (CTLA4, $49 \mathrm{~A} \rightarrow \mathrm{G}$ (T17A)), apolipoprotein E (APOE, e2, e3, e4 alleles), haemochromatosis gene $(\mathrm{HFE}, 845 \mathrm{G} \rightarrow \mathrm{A}(\mathrm{C} 282 \mathrm{Y})$ and $187 \mathrm{C} \rightarrow \mathrm{G}(\mathrm{H} 63 \mathrm{D}))$, low density lipoprotein receptor (LDLR, $1170 \mathrm{G} \rightarrow \mathrm{A}, \mathrm{A} 370 \mathrm{~T}$ ), and myeloperoxidase $(\mathrm{MPO},-463 \mathrm{G} \rightarrow \mathrm{A}$ ) were detected by PCR as previously described. ${ }^{13-15}$ 19-21 The dimorphism in the superoxide dismutase 2 mitochondrial (SOD2) targeting sequence was detected by PCR with oligonucleotide primers 5'CTG ACC GGG CTG TGC TTT CTC G'3 (forward) and 5'CTC CCG CCG CTC AGC CTG GAC C'3 (reverse), which amplified a $258 \mathrm{bp}$ fragment of DNA containing the polymorphism. Identification of the two alleles at the dimorphic site was performed by agarose gel electrophoresis (2.5\%) after incubating the PCR product for $4 \mathrm{~h}$ with $\mathrm{BsaWl}$. Cleavage with this restriction enzyme when a $\mathrm{T}$ (Val) was present at position 1183 (residue 16) produced two fragments of 48 and $210 \mathrm{bp}$ in length. The uncut $258 \mathrm{bp}$ fragment allowed identification of the C (Ala) allele. The CC chemokine receptor 5 (CCR5) insertion/deletion $(\Delta 32)$ polymorphism was detected by PCR with oligonucleotide primers 5'ACC TGC AGC TCT CAT TTT CC'3 (forward) and 5'GCA GAT GAC CAT GAC AAG $\mathrm{CA}^{\prime} 3$ (reverse), which produced either 79 or $111 \mathrm{bp}$ products corresponding to the $\Delta 32$ or the wild type allele, respectively. All samples were amplified and digested in parallel with three samples of known genotype and water. Some of the patients' DNA did not amplify for each of the polymorphisms examined. The number of samples that failed to amplify was four for HFE C282Y, two for MTP, two for APOE, one for CCR5, six for SOD2, and four for CTLA4.

\section{Statistical analysis}

Data are summarised as mean (standard deviation) or median (range). Differences in the levels of characteristics between subjects with slowly progressing versus rapidly progressing liver disease were compared using Student's $t$ test or the Mann-Whitney test. Differences in the mean probability of having rapidly progressing fibrosis between groups were compared using ANOVA.

The crude influence of genotypes on the rate of fibrosis progression category was tested using the Pearson $\chi^{2}$ test or the Mantle-Haenszel $\chi^{2}$ test for a linear trend. Logistic regression was used to assess the simultaneous effect of the genetic polymorphisms after adjusting for potential confounding by gender, age at infection, age at biopsy, viral genotype, and body mass index (BMI). Due to the inherent difficulty in obtaining a reliable alcohol history from HCV infected individuals, alcohol was not considered in the logistic regression model. A backward elimination approach was used to remove non-significant variables and determine the most parsimonious model. Quantitative variables were not dichotomised and for viral genotype, four groupings were separately tested ( $1 v 2 v 3,1 v 3,1 v$ non-1, or $3 v$ non-3). The goodness of fit of the logistic regression model was tested using the Hosmer and Lemeshow test, and the model was found to be appropriate for the data $(p=0.328)$. Odds ratios (with $95 \%$ confidence intervals) were calculated to estimate the risk of more rapidly progressing liver fibrosis associated with each polymorphism.

Results from logistic regression analysis were used as the basis for determining which variables best predicted clinical 
prognosis. The predictive equation (from the logistic model), shown below, was used to describe the expected probability of having rapidly progressing liver disease as a function of the identified risk factors and genotypes.

Probability of having rapidly progressing fibrosis

$$
=1 /\left\{1+\operatorname{Exp}\left[-\left(\beta_{0}+\left(\beta_{i} \times Q_{i}\right)\right)\right]\right\}
$$

where $\beta_{0}$ is a constant, $\beta_{i}$ is the predictive regression coefficient value for each risk factor, and $Q_{i}$ is the presence of an environmental factor or profibrotic genotype (being either 1 for yes or 0 for no). ${ }^{22}$ The regression model assigns a coefficient to each item in the model $\left(\beta_{i}\right)$; this coefficient weights the item according to its importance in determining each individual's risk of rapidly progressing fibrosis. Applying this equation to the risk factors and genotypes of a second cohort, each patient's expected probability of having rapidly progressing fibrosis was calculated.

SPSS version 12.0 (http://www.spss.com) was used for all analyses and a value of $\mathrm{p}<0.05$ was considered statistically significant. To prepare graphical illustrations GraphPad Prism version 4.02 (http://www.graphpad.com/) was used.

\section{RESULTS}

\section{Patient characteristics}

In our cohort of 326 patients with chronic HCV, the median rate of progression of fibrosis was 0.13 fibrosis units per year, identical to previous estimates from cross-sectional studies on very large numbers of patients. ${ }^{3}$ However, within this cohort, the rate of fibrosis progression was not normally distributed, and varied greatly between individuals. Using strict classification for the selection of a training set (fig l), 83 subjects $(25.3 \%)$ had rapid progression of fibrosis $(0.186$ fibrosis units per year) with cirrhosis or the presence of septal fibrosis on a liver biopsy performed within 10 years of acquisition of HCV. Sixty six subjects (20.1\%) had slow fibrosis progression (0.037 fibrosis units per year) with no fibrosis or portal fibrosis only on liver biopsy after 20 years of infection. Those patients with neither rapid nor slow fibrosis progression according to these strict criteria $(n=177)$ were not included in the comparative analysis for this training set. In comparison with slow progressors, subjects with rapid progression of fibrosis were infected at an older age and had a higher grade of hepatic inflammation and steatosis (table 1). Although these factors have previously been shown to contribute to disease severity, they account for only a portion of the variability in fibrosis progression. ${ }^{2}$ Twenty one patients had acquired HCV before the age of 15 years: 15 were in the slow progression group and six in the rapid progression group. None had a history of haematologic disease.
Serological signs of a former HBV infection were present in $42 \%$ of slow progressors and $41 \%$ of rapid progressors.

\section{Determination of progression associated alleles in subjects with chronic HCV and non-progressive or progressive fibrosis}

Using results from adjusted and unadjusted analyses, progression associated alleles were assigned for each gene as follows: CTLA4, homozygotes (AA or GG); APOE, absence of a $\epsilon 4$ allele; SOD2, Val/Val or Ala/Val; CCR5, wild type; MTP, homozygotes (TT or GG); HFE, at least one of C282Y or H63D. An association between polymorphisms in the MPO or LDLR genes and rapidly progressing fibrosis was not observed in our cohort (not shown). The frequencies of progression associated genotypes in patients with slow or rapid progression of fibrosis are presented in table 2. The odds ratios for having rapidly progressing fibrosis for each allele ranged from 1.6 to 2.7 following univariate analysis and from 2.1 to 4.5 following multivariate analysis.

The number of progression associated alleles for each patient was summed. The cumulative frequency of patients possessing increasing numbers of progression associated alleles was significantly higher in patients with rapidly progressing fibrosis $(p=0.003)$. The association between rapidly progressing fibrosis and possession of $\geqslant 3, \geqslant 4$, or $\geqslant 5$ progression associated alleles was determined and the odds ratios for having rapidly progressing fibrosis increased with increasing number of progression associated alleles (table 3 ).

\section{Prediction of rapidly progressing fibrosis in a second cohort}

Using results from the logistic regression analysis for the training cohort, a predictive equation and the receiver operating characteristic curve (ROC) were constructed. The area under the ROC was 0.868 . The predictive equation was applied to a second, validation cohort of patients with more rapidly progressing fibrosis, comprising 24 liver transplant recipients (three females) in addition to $11 \mathrm{HCV}$ patients (four females) identified from group 1 of HCV patients. While these group 1 pre-transplant HCV patients did not meet the very strict criteria for inclusion in the training set, they nevertheless had fibrosis stage 2 on biopsy between 10 and 14 years following acquisition of infection and rate of fibrosis progression ranging from 0.134 to 0.182 fibrosis units per year (which is 3.6- to 4.9-fold higher than that of the slow progressors). In this validation cohort, no patient had no or one profibrotic genotype, four patients had two, eight patients had three, 12 patients had four, nine patients had five, and two patients had six profibrotic genotypes. Using a

Table 1 Demographic, clinical, and histological characteristics

\begin{tabular}{|c|c|c|c|c|}
\hline & \multirow[b]{2}{*}{ Total group } & \multicolumn{2}{|c|}{ Rate of fibrosis progression } & \multirow[b]{2}{*}{$p$ for slow $v$ rapid } \\
\hline & & Slow & Rapid & \\
\hline $\mathrm{n}$ & 326 & 66 & 83 & \\
\hline Gender, F/M & $102 / 224$ & $17 / 49$ & $17 / 66$ & 0.556 \\
\hline Age at biopsy, mean years (SD) & $39.5(7.7)$ & $42.1(4.5)$ & $43.2(9.0)$ & 0.35 \\
\hline Age at infection, mean years (SD) & $21.8(8.2)$ & $16.5(6.0)$ & $24.7(10.6)$ & $<0.0001$ \\
\hline Duration of infection, mean years (SD) & $17.6(8.5)$ & $25.6(5.3)$ & $18.3(8.8)$ & N/A \\
\hline Fibrosis progression, median units/year & 0.131 & 0.032 & 0.184 & N/A \\
\hline $\mathrm{BMI}$, mean $\mathrm{kg} / \mathrm{m}^{2}$ (SD) & $26.0(4.7)$ & $25.8(4.0)$ & $27.3(4.9)$ & 0.067 \\
\hline Current ethanol, median g/day & 1.8 & 2 & 0.5 & 0.570 \\
\hline Previous ethanol, median g/day & 30 & 42.5 & 50 & 0.784 \\
\hline Stage of fibrosis, median & 1 & 1 & 3 & N/A \\
\hline Portal inflammation, median & 2 & 1 & 2 & $<0.0001$ \\
\hline Lobular inflammation, median & 1 & 1 & 1 & 0.003 \\
\hline Grade of steatosis, median & 0 & 0 & 1 & $<0.0001$ \\
\hline Perls', median & 0 & 0 & 0 & 0.149 \\
\hline Viral genotype, $1 / 2 / 3$ & $107 / 10 / 88$ & $27 / 6 / 20$ & $32 / 3 / 26$ & 0.437 \\
\hline
\end{tabular}

$S D$, standard deviation. N/A, not applicable; $p$ values are inappropriate for these variables as they contribute to the definition of slow and rapid progressors. 
Table 2 Frequencies of progression associated genotypes in patients with slow or more rapidly progressing fibrosis

\begin{tabular}{|c|c|c|c|c|c|c|c|}
\hline \multirow[b]{2}{*}{ Gene } & \multirow{2}{*}{$\begin{array}{l}\text { Progression associated } \\
\text { genotype }\end{array}$} & \multicolumn{2}{|c|}{ Rate of fibrosis progression } & \multirow[b]{2}{*}{$\mathbf{p}$} & \multirow[b]{2}{*}{ Odds ratio $(95 \% \mathrm{Cl})$} & \multirow[b]{2}{*}{ Adjusted p† } & \multirow{2}{*}{$\begin{array}{l}\text { Adjusted odds } \\
\text { ratiot }(95 \% \mathrm{Cl})\end{array}$} \\
\hline & & Slow, n (\%)* & Rapid, n (\%)* & & & & \\
\hline \multirow[t]{2}{*}{ HFE } & Yes (C282Y or H63D) & $19(35.8)$ & $34(64.2)$ & \multirow[t]{2}{*}{0.122} & $1.8(0.9$ to 3.6$)$ & \multirow[t]{2}{*}{0.004} & $4.5(1.6$ to 12.2$)$ \\
\hline & No & $46(49.5)$ & $47(50.5)$ & & 1.0 (ref) & & 1.0 (ref) \\
\hline \multirow[t]{2}{*}{ MTP } & Yes (TT or GG) & $36(36.0)$ & $64(64.0)$ & \multirow[t]{2}{*}{0.008} & 2.7 (1.3 to 5.4$)$ & \multirow[t]{2}{*}{0.005} & $4.1(1.5$ to 10.9$)$ \\
\hline & No & $28(59.6)$ & $19(40.4)$ & & 1.0 (ref) & & 1.0 (ref) \\
\hline \multirow[t]{2}{*}{ APOE } & Yes (no $\in 4$ ) & $41(40.6)$ & $60(59.4)$ & \multirow[t]{2}{*}{0.213} & $1.6(0.8$ to 3.3$)$ & \multirow[t]{2}{*}{0.017} & $3.6(1.3$ to 10.1$)$ \\
\hline & No & $24(52.2)$ & $22(47.8)$ & & 1.0 (ref) & & 1.0 (ref) \\
\hline \multirow[t]{2}{*}{ CCR5 } & Yes (wild type) AV) & $49(41.2)$ & $70(58.8)$ & \multirow[t]{2}{*}{0.100} & $2.1(0.9$ to 4.7$)$ & \multirow[t]{2}{*}{0.044} & $3.3(1.1$ to 10.1$)$ \\
\hline & No & $17(58.6)$ & $12(41.4)$ & & 1.0 (ref) & & 1.0 (ref) \\
\hline \multirow{2}{*}{ SOD2 } & Yes (TT or TC) & 37 (36.6) & $64(63.4)$ & \multirow{2}{*}{0.016} & 2.5 (1.2 to 5.3$)$ & \multirow[t]{2}{*}{0.044} & $2.8(1.03$ to 7.4$)$ \\
\hline & No & $25(59.5)$ & $17(40.5)$ & & 1.0 (ref) & & 1.0 (ref) \\
\hline \multirow[t]{2}{*}{ CTLA4 } & Yes (AA or GG) & $23(33.3)$ & $46(66.7)$ & \multirow[t]{2}{*}{0.029} & 2.3 (1.2 to 4.5$)$ & \multirow[t]{2}{*}{0.101} & $2.1(0.9$ to 5.2$)$ \\
\hline & No & $40(52.6)$ & $36(47.4)$ & & 1.0 (ref) & & 1.0 (ref) \\
\hline
\end{tabular}

*Row percentages; tvariables considered in the analysis included age at infection, gender, viral genotype, and BMI. $95 \% \mathrm{Cl}, 95 \%$ confidence interval.

cut off value for the predicted probability of 0.5 , the predictive equation correctly classified $80 \%$ of patients in this validation cohort as having more rapidly progressing fibrosis. Using a model that included patient demographic variables only (that is, excluding progression associated genes), the best predictive equation that could be constructed correctly classified only $42 \%$ of these patients.

\section{Application of the model to patients with an intermediate rate of fibrosis progression}

The model calculates, for each patient, the predictive probability of having rapidly progressing fibrosis. The predictive probability value can range from 0 to 1 , with a value closer to 1 indicating a greater likelihood of more rapid fibrosis progression and a value closer to 0 indicating a greater likelihood of slow fibrosis progression. To determine whether the model (which employed strictly classified slow and rapid progressors to generate the predictive equation) would be applicable to patients with an intermediate rate of fibrosis progression, a cohort of probable intermediate progressors was identified from group 1. These patients $(n=30)$ had stage 2 fibrosis on biopsy more than 20 years after acquisition of infection. Not surprisingly, the mean probability of having rapidly progressing fibrosis for this fibrosis stage $2>20$ year cohort $(0.57$ (SD 0.33$)$ ) was intermediate between the slow $(0.33$ (SD 0.24)) and rapid progressors $(0.74(\mathrm{SD} 0.25))(\mathrm{p}<0.01$ and $\mathrm{p}<0.05$, respectively).

\section{DISCUSSION}

In this study, we demonstrate an association between HFE, MTP, APOE, CCR5, CTLA4, and SOD2 genotypes and the presence of progressive fibrosis in patients with chronic HCV. When inheritance of the genotypes was considered together, the odds of having progressive fibrosis increased with the number of progression associated genetic variants. In a second cohort of patients with advanced fibrosis, the predictive equation correctly classified $80 \%$ of patients as having rapidly progressing fibrosis. These findings lend additional weight to the involvement of host genetic factors in the variability in progression of this disease and suggest that it may ultimately be feasible to compile a simple genomic profile that better predicts an individual's risk of developing progressive fibrosis.

Fibrogenesis is a complex process, driven by a number of concurrent pathways involving oxidative stress, inflammation, and steatosis. ${ }^{2}$ Genetic variation may occur at various sites within these pathways to influence the development of fibrosis. The genetic polymorphisms examined in this study have a plausible link with cellular injury or fibrogenesis and have been shown to have functional significance. The CC chemokine receptor 5 (CCR5) is expressed by a major subset of CD8+ cytotoxic T lymphocytes (CTL) in addition to T helper (Th) cells producing type 1 cytokines such as interferon- $\gamma$ and tumour necrosis factor. T cells infiltrating HCV infected livers express high levels of $\mathrm{CCR}^{23}$ and may contribute to immune mediated liver injury as evidenced by increased intrahepatic expression of Thl associated cytokines in patients with progressive fibrosis. ${ }^{24}$ Similarly, CTLA4 may also modulate the extent of hepatic inflammation which is a dominant factor in the development of fibrosis. ${ }^{25}$ CTLA4 is expressed on activated CD4+ and CD8+ T cells. It down modulates $\mathrm{T}$ cell responses following binding to the ligands B7-1 and B7-2. ${ }^{26}$

Reactive oxygen species (ROS) have been increasingly implicated in the production of liver injury in chronic HCV. ${ }^{27}$ Inherited mutations in the HFE gene (C282Y heterozygosity or H63D) may result in relatively modest cellular iron accumulation ${ }^{28}$ that may nevertheless increase the production of ROS leading to activation of hepatic stellate cells. ${ }^{29}$ The mitochondrial enzyme SOD2 is responsible for the initial step in detoxifying ROS. $^{30}$ More recently, steatosis has been recognised as a co-factor in the progression of fibrosis in chronic HCV. As a consequence, polymorphisms in genes concerned with hepatic triglyceride storage and export may

Table 3 The association between rapidly progressing fibrosis and possession of increasing number of progression associated alleles

\begin{tabular}{|c|c|c|c|c|c|c|}
\hline \multirow{2}{*}{$\begin{array}{l}\text { No. of profibrotic } \\
\text { genotypes }\end{array}$} & \multicolumn{2}{|c|}{ Rate of fibrosis progression } & \multirow[b]{2}{*}{$\mathbf{p}$} & \multirow[b]{2}{*}{ Odds ratio $(95 \% \mathrm{Cl})$} & \multirow[b]{2}{*}{ Adjusted $\mathrm{p} \dagger$} & \multirow{2}{*}{$\begin{array}{l}\text { Adjusted odds } \\
\text { ratiot }(95 \% \mathrm{Cl})\end{array}$} \\
\hline & Slow, n (\%) & Rapid, n (\%) & & & & \\
\hline$<3$ & $13(72.2)$ & $5(27.8)$ & & & & \\
\hline$\geqslant 3$ & 46 (39) & $72(61)$ & 0.008 & 4.1 (1.4 to 12.8$)$ & 0.002 & 9.1 (2.2 to 37.3$)$ \\
\hline$\geqslant 4$ & $22(28.2)$ & $56(71.8)$ & 0.0005 & $6.6(2.1$ to 12.8$)$ & $<0.0001$ & 15.5 (3.4 to 70$)$ \\
\hline$\geqslant 5$ & $5(15.2)$ & $28(84.8)$ & $<0.0001$ & 14.6 (3.6 to 59.3 & $<0.0001$ & 24.1 (4.3 to 136$)$ \\
\hline
\end{tabular}

*Row percentages; †variables considered in the analysis included age at infection, gender, viral genotype, and BMI.

$95 \% \mathrm{Cl}, 95 \%$ confidence interval. 
have an effect on the rate of disease progression. Within the hepatocyte, MTP has a role in the assembly and secretion of apolipoprotein B containing lipoproteins. ${ }^{31}$ Some evidence suggests that the HCV life cycle involves cellular lipid metabolism $^{32}$ and that lipoprotein particles may facilitate entry of virus into cells. ${ }^{33}$ As a component of several lipoprotein classes, APOE has an important role in plasma lipoprotein metabolism.

Some of the polymorphisms assessed in this study such as CCR5 $\Delta 32$, are associated with a clear cut change in protein function, ${ }^{34}$ whereas the biological consequences of allelic variation in genes such as SOD2 are currently less clear. An association between fibrosis and an allelic variant does not necessarily imply that the allele is functionally responsible, since the association may occur through linkage disequilibrium. ${ }^{8}$ Nevertheless, irrespective of the specific biological mechanisms involved, these genotypes were associated with disease outcome in prior studies in addition to our cohort of subjects with chronic HCV.

Although a number of previous studies identified a relationship between these genetic polymorphisms and hepatic fibrosis, ${ }^{9-1735}$ the associations have not been confirmed in all studies ${ }^{36-42}$ and some have found that the alternate genotype confers the increased risk of fibrosis. ${ }^{11}{ }^{17} \mathrm{~A}$ number of factors may account for these inconsistent results including racial heterogeneity in different populations, confounding or interactions from other genetic or environmental factors, and low sample sizes. ${ }^{616}$ In particular, methodological differences in determining the severity of fibrosis or risk of progressive disease are likely to be important. $^{8}$ Many earlier studies examined the association between genotypes and the stage of hepatic fibrosis without categorisation of patients as slow or rapid progressors on the basis of both histological stage of fibrosis and duration of infection. In this study we used strict criteria to categorise subjects and, although this limited the number of subjects that met the classification criteria, we believe it provided a more robust assessment of the rate of disease progression. Unfortunately, no readily obtainable group of slow progressors was available for the validation cohort, and we acknowledge that inclusion of only rapid progressors in this analysis limits our ability to identify the false positive rate of our predictive model. However, the results are still important in terms of the ability of the model to detect true rapid progressors.

Individually, the genetic polymorphisms are weak risk factors for fibrosis, with limited clinical value for predicting disease severity if used one at a time. ${ }^{43}$ However, we found that the combined effect of several profibrotic genetic polymorphisms markedly influenced the risk of developing progressive fibrosis. Our study examined only a small number of genotypes and since this work was undertaken, a number of additional genetic associations with fibrosis have been reported. ${ }^{16}{ }^{44-46}$ With the rapid discovery of single nucleotide polymorphisms and the development of high throughput genotyping, many new disease susceptibility markers will be identified. ${ }^{47}$ Ultimately, using a panel of progression associated genotypes, it may be possible to predict an individual's risk of developing progressive fibrosis in the setting of chronic HCV infection.

This approach has been examined in Helicobacter pylori infected individuals, in whom a proinflammatory genetic profile was shown to increase the risk of chronic atrophic gastritis and gastric carcinoma. ${ }^{48}$ There is currently much interest in the concept of using genetic variants at multiple loci or genomic profiling to measure susceptibility to common complex diseases. ${ }^{43}{ }^{49}$ Statistical modelling has been used to illustrate the fact that disease prediction for common multifactorial diseases is greatly improved by considering multiple predisposing genotypes and environmental factors concurrently. ${ }^{50}$ These authors argue that "...according to this multifactorial model, disease will develop only in subjects whose combined burden of genetic and environmental risk factors exceeds a certain threshold..."..$^{50}$

In conclusion, we believe that an approach which uses strict phenotypic classification in combination with investigation of multiple genetic loci will allow the determination of a genetic profile that can predict those patients with chronic HCV who are at risk of rapid disease progression and therefore warrant more aggressive therapeutic management. Such an approach studying a large cohort of patients across multiple centres could provide a prognostic index that is universally applicable.

\section{ELECTRONIC-DATABASE INFORMATION}

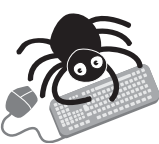

Details of SPSS version 12.0 can be found at http:// www.spss.com and of GraphPad Prism version 4.02 at http://www.graphpad.com/

\section{Authors' affiliations}

M M Richardson, E E Powell, H D Barrie, A D Clouston, J R Jonsson, School of Medicine, Southern Clinical Division, The University of Queensland, Brisbane, Australia

E E Powell, Department of Gastroenterology and Hepatology, Princess Alexandra Hospital, Brisbane, Australia

A D Clouston, Concord Repatriation General Hospital, Sydney, Australia

D M Purdie, Northern California Cancer Center, Fremont, CA, USA

Funding for this study was provided by The Perpetual Philanthropic Foundations, The Lions Medical Research Foundation, The Queensland Liver Transplant Trust Fund, The Princess Alexandra Hospital Foundation, The National Health and Medical Research Council, and The Royal Children's Hospital Foundation.

Competing interests: none declared

Correspondence to: Dr Julie R Jonsson, University of Queensland, School of Medicine, Southern Division, Level 3, R Wing, Princess Alexandra Hospital, Ipswich Road, Woolloongabba, QLD, 4102, Australia; J.Jonsson@uq.edu.au

Revised version received 15 April 2005

Accepted for publication 25 April 2005

\section{REFERENCES}

1 Kim WR. The burden of hepatitis $C$ in the United States. Hepatology 2002;36(5 suppl 1):S30-4.

2 Marcellin P, Asselah T, Boyer N. Fibrosis and disease progression in hepatitis C. Hepatology 2002;36(5 suppl 1):S47-56

3 Poynard T, Bedossa P, Opolon P. Natural history of liver fibrosis progression in patients with chronic hepatitis C. The OBSVIRC, METAVIR, CLINIVIR, and DOSVIRC groups. Lancet 1997;349(9055):825-32.

4 Hourigan LF, Macdonald GA, Purdie D, Whitehall VH, Shorthouse C, Clouston A, Powell EE. Fibrosis in chronic hepatitis $C$ correlates significantly with body mass index and steatosis. Hepatology 1999;29(4):1215-9.

5 Wright M, Goldin R, Fabre A, Lloyd J, Thomas H, Trepo C, Pradat P, Thursz $M$; HENCORE collaboration. Measurement and determinants of the natural history of liver fibrosis in hepatitis $C$ virus infection: a cross sectional and longitudinal study. Gut 2003;52(4):574-9.

6 Bataller R, North KE, Brenner DA. Genetic polymorphisms and the progression of liver fibrosis: a critical appraisal. Hepatology 2003;37(3):493-503

7 loannidis JP. Genetic associations: false or true? Trends Mol Med 2003;9(4):135-8.

8 Yee $\mathbf{L}$. Host genetic determinants in hepatitis $\mathrm{C}$ virus infection. Genes Immun 2004;5(4):237-45.

9 Smith BC, Gorve J, Guzail MA, Day CP, Daly AK, Burt AD, Bassendine MF. Heterozygosity for hereditary hemochromatosis is associated with more fibrosis in chronic hepatitis C. Hepatology 1998;27(6): 1695-9.

10 Day CP, Chen Y, Argarwal K, Daly AK. CTLA4 gene polymorphism associated with autoimmune disease is a risk factor for advanced alcoholic liver disease. Hepatology 1999;30(4): 1307.

11 Degoul F, Sutton A, Mansouri A, Cepanec C, Degott C, Fromenty B, Beaugrand M, Valla D, Pessayre D. Homozygosity for alanine in the 
mitochondrial targeting sequence of superoxide dismutase and risk for severe alcoholic liver disease. Gastroenterology 2001;120(6):1468-74.

12 Wozniak MA, ltzhaki RF, Faragher EB, James MW, Ryder SD, Irving WL; Trent HCV Study Group. Apolipoprotein E-epsilon 4 protects against severe liver disease caused by hepatitis C virus. Hepatology 2002;36(2):456-63.

13 Hennig BJ, Hellier S, Frodsham AJ, Zhang L, Klenerman P, Knapp S, Wright M, Thomas HC, Thursz M, Hill AV. Association of low-density lipoprotein receptor polymorphisms and outcome of hepatitis $\mathrm{C}$ infection. Genes Immun 2002;3(6):359-67.

14 Reynolds WF, Patel K, Pianko S, Blatt LM, Nicholas JJ, McHutchison JG. A genotypic association implicates myeloperoxidase in the progression of hepatic fibrosis in chronic hepatitis C virus infection. Genes Immun 2002;3(6):345-9.

15 Erhardt A, Maschner-Olberg A, Mellenthin C, Kappert G, Adams O, Donner A, Willers R, Niederau C, Haussinger D. HFE mutations and chronic hepatitis C: H63D and C282Y heterozygosity are independent risk factors for liver fibrosis and cirrhosis. J Hepatol 2003;38(3):335-42.

16 Hellier S, Frodsham AJ, Hennig BJ, Klenerman P, Knapp S, Ramaley P, Satsangi J, Wright $M$, Zhang L, Thomas HC, Thursz M, Hill AV. Association of genetic variants of the chemokine receptor CCR5 and its ligands, RANTES and MCP-2, with outcome of HCV infection. Hepatology 2003;38(6):1468-76.

17 Namikawa C, Shu-Ping Z, Vyselaar JR, Nozaki Y, Nemoto Y, Ono M, Akisawa N, Saibara T, Hiroi M, Enzan H, Onishi S. Polymorphisms of microsomal triglyceride transfer protein gene and manganese superoxide dismutase gene in non-alcoholic steatohepatitis. J Hepatol 2004;40(5):781-6.

18 Schever PJ. Classification of chronic viral hepatitis: a need for reassessment. $J$ Hepatol 1991;13(3):372-4.

19 Karpe F, Lundahl B, Ehrenborg E, Eriksson P, Hamsten A. A common functional polymorphism in the promoter region of the microsomal triglyceride transfer protein gene influences plasma LDL levels. Arterioscler Thromb Vasc Biol 1998; 18(5):756-61

20 Agarwal K, Jones DE, Daly AK, James OF, Vaidya B, Pearce S, Bassendine MF. CTLA-4 gene polymorphism confers susceptibility to primary biliary cirrhosis. J Hepatol 2000;32(4):538-41.

21 Wenham PR, Price WH, Blandell G. Apolipoprotein E genotyping by onestage PCR. Lancet 1991:337(8750):1158-9.

22 Kleinbaum DG, Kupper LL, Muller KE. Applied regression analysis and other multivariate methods, 2nd ed. Belmont, CA: Duxbury Press, 1988.

23 Shields PL, Morland CM, Salmon M, Qin S, Hubscher SG, Adams DH. Chemokine and chemokine receptor interactions provide a mechanism for selective T cell recruitment to specific liver compartments within hepatitis Cinfected liver. J Immunol 1999;163(11):6236-43

24 Napoli J, Bishop GA, McGuinness PH, Painter DM, McCaughan GW. Progressive liver injury in chronic hepatitis $\mathrm{C}$ infection correlates with increased intrahepatic expression of Th1-associated cytokines. Hepatology 1996;24(4):759-65

25 Maher JJ. Interactions between hepatic stellate cells and the immune system. Semin Liver Dis 2001:21(3):417-26.

26 Chambers CA, Allison JP. Costimulatory regulation of T cell function. Curr Opin Cell Biol 1999; 11(2):203-10.

27 Okuda M, Li K, Beard MR, Showalter LA, Scholle F, Lemon SM, Weinman SA. Mitochondrial injury, oxidative stress, and antioxidant gene expression are induced by hepatitis C virus core protein. Gastroenterology 2002;122(2):366-75

28 Bomford A. Genetics of haemochromatosis. Lancet 2002;360(9346):1673-81.

29 Pietrangelo A. Iron-induced oxidant stress in alcoholic liver fibrogenesis. Alcohol 2003;30(2): 121-9.

30 Wallace DC. Mitochondrial diseases in man and mouse. Science 1999.283(5407):1482-8

31 Wefterau JR, Lin MC, Jamil H. Microsomal triglyceride transfer protein Biochim Biophys Acta 1997;1345(2):136-50.

32 Su Al, Pezacki JP, Wodicka L, Brideau AD, Supekova L, Thimme R, Wieland S, Bukh J, Purcell RH, Schultz PG, Chisari FV. Genomic analysis of the host response to hepatitis C virus infection. Proc Natl Acad Sci U S A 2002;99(24): 15669-74.
33 Agnello V, Abel G, Elfahal M, Knight GB, Zhang QX. Hepatitis $C$ virus and other flaviviridae viruses enter cells via low density lipoprotein receptor. Proc Natl Acad Sci U S A 1999;96(22): 12766-71.

34 Liu R, Paxton WA, Choe S, Ceradini D, Martin SR, Horuk R, MacDonald ME, Stuhlmann H, Koup RA, Landau NR. Homozygous defect in HIV-1 coreceptor accounts for resistance of some multiply-exposed individuals to HIV-1 infection. Cell 1996;86(3):367-77.

35 Valenti L, De Feo T, Fracanzani AL, Fatta E, Salvagnini M, Arico S, Rossi G, Fiorelli G, Fargion S. Cytotoxic T-lymphocyte antigen-4 A49G polymorphism is associated with susceptibility to and severity of alcoholic liver disease in Italian patients. Alcohol Alcohol 2004;39(4):276-80.

36 Stewart SF, Leathart JB, Chen Y, Daly AK, Rolla R, Vay D, Mottaran E, Vidali $M$, Álbano $E$, Day CP. Váline-alanine manganese superoxide dismutase polymorphism is not associated with alcohol-induced oxidative stress or liver fibrosis. Hepatology 2002;36(6):1355-60.

37 Gehrke SG, Stremmel W, Mathes I, Riedel HD, Bents K, Kallinowski B. Hemochromatosis and transferrin receptor gene polymorphisms in chronic hepatitis C: impact on iron status, liver injury and HCV genotype. J Mol Med 2003:81(12):780-7.

38 Bonkovsky HL, Troy N, McNeal K, Banner BF, Sharma A, Obando J, Mehta S, Koff RS, Liu Q, Hsieh CC. Iron and HFE or TFR1 mutations as comorbid factors for development and progression of chronic hepatitis $C$. J Hepatol 2002;37(6):848-54.

39 Hellier SC, Satsangi JJ, Christie JM, Chapman RW, Ken WI. Chemokine receptor CCR5 polymorphisms do not affect the disease progression in hepatitis C virus infection. Gastroenterology 2000;118(4):A943.

40 Promrat K, McDermott DH, Gonzalez CM, Kleiner DE, Koziol DE, Lessie M, Merrell M, Soza A, Heller T, Ghany M, Park Y, Alter HJ, Hoofnagle JH, Murphy PM, Liang TJ. Associations of chemokine system polymorphisms with clinical outcomes and treatment responses of chronic hepatitis $C$. Gastroenterology 2003;124(2):352-60.

41 Mangia A, Santoro R, D'Agruma L, Andriulli A. HCV chronic infection and CCR5-delta32/delta32. Gastroenterology 2003;124(3):868-9; author reply 869-70

42 Wasmuth HE, Werth A, Mueller T, Berg T, Dietrich CG, Geier A, SchirinSokhan R, Gartung C, Lorenzen J', Matern S, Lammert F. CC chemokine receptor 5 delta32 polymorphism in two independent cohorts of hepatitis $C$ virus infected patients without hemophilia. J Mol Med 2004:82(1):64-9.

43 Khoury MJ, Yang Q, Gwinn M, Little J, Dana Flanders W. An epidemiologic assessment of genomic profiling for measuring susceptibility to common diseases and targeting interventions. Genet Med 2004;6(1):38-47.

44 Muhlbaver M, Bosserhoff AK, Hartmann A, Thasler WE, Weiss TS, Herfarth H, Lock G, Scholmerich J, Hellerbrand C. A novel MCP-1 gene polymorphism is associated with hepatic MCP-1 expression and severity of HCV-related liver disease. Gastroenterology 2003; 125(4):1085-93.

45 Goyal A, Kazim SN, Sakhuja P, Malhotra V, Arora N, Sarin SK. Association of TNF-beta polymorphism with disease severity among patients infected with hepatitis C virus. J Med Virol 2004;72(1):60-5.

46 Wright M, Goldin R, Hellier S, Knapp S, Frodsham A, Hennig B, Hill A, Apple R, Cheng S, Thomas H, Thursz M. Factor V Leiden polymorphism and the rate of fibrosis development in chronic hepatitis $\mathrm{C}$ virus infection. Gut 2003;52(8): 1206-10.

47 Saito T, Ji G, Shinzawa H, Okumoto K, Hattori E, Adachi T, Takeda T, Sugahara K, Ito Jl, Watanabe H, Saito K, Togashi H, Ishii K, Matsuura T, Inageda K, Muramatsu M, Kawata S. Genetic variations in humans associated with differences in the course of hepatitis $C$. Biochem Biophys Res Commun 2004:317(2):335-41.

48 Machado JC, Figueiredo C, Canedo P, Pharoah P, Carvalho R, Nabais S, Castro Alves C, Campos ML, Van Doorn L, Caldas C, Seruca R, Carneiro F, Sobrinho-Simoes M. A proinflammatory genetic profile increases the risk for chronic atrophic gastritis and gastric carcinoma. Gastroenterology 2003; 125(2):364-71

49 Khoury MJ. Genetics and genomics in practice: the continuum from genetic disease to genetic information in health and disease. Genet Med 2003;5(4):261-8

50 Yang Q, Khoury MJ, Botto L, Friedman JM, Flanders WD. Improving the prediction of complex diseases by testing for multiple disease-susceptibility genes. Am J Hum Genet 2003;72(3):636-49. 